\title{
Stock Identification of Chum Salmon Overwintering in the Gulf of Alaska by Using a New SNP Baseline
}

\author{
Shigehiko Urawa ${ }^{1}$, Terry Beacham ${ }^{2}$, Ben Sutherland ${ }^{2}$, and Shunpei Sato ${ }^{1}$ \\ ${ }^{I}$ Fisheries Research Institute, Japan Fisheries Research and Education Agency, 2-2 Nakanoshima, Toyohira-ku, \\ Sapporo 062-0922, Japan \\ ${ }_{2}^{2}$ Pacific Biological Station, Fisheries and Oceans Canada, 3190 Hammond Bay Road, Nanaimo, BC, Canada
}

Keywords: chum salmon, Gulf of Alaska, winter, distribution, stock composition, SNP analysis

The Gulf of Alaska is an important winter habitat for chum salmon originating from both the continents of North America and Asia (Urawa et al. 1997, 2016; Beacham et al. 2009). There is, however, limited knowledge of their stock-specific distribution, abundance, and survival in winter.

An international cooperative expedition was conducted in the Gulf of Alaska between February 16 and March 18, 2019, onboard the Russian R/V Professor Kaganovskiy (Pakhomov et al. 2019). A total of 223 chum salmon were caught by a surface trawl, which was the most abundant catch among Pacific salmon. Although chum salmon were widely distributed in the survey area $\left(47-56^{\circ} \mathrm{N}, 137-147^{\circ} \mathrm{W}\right)$, they were relatively abundant in southwestern warm waters. The SST of chum salmon habitats averaged $6.7^{\circ} \mathrm{C}$, ranging between $5.0^{\circ} \mathrm{C}$ and $7.5^{\circ} \mathrm{C}$.

The regional origin of individual fish was estimated by using a new Pacific-rim SNP baseline (545 SNPs, 400 populations) developed by the Pacific Biological Station. The SNP analysis confirmed that chum salmon in the Gulf of Alaska during winter were a mixture of various populations: $22.0 \%$ Japan, $20.2 \%$ Russia, $14.8 \%$ West Alaska, 5.1\% Yukon River, 6.5\% Central Alaska, 11.2\% Southeast Alaska (SEAK), 16.5\% British Columbia (BC), and $3.7 \%$ Washington. In ocean age (OA)-1 fish, SEAK and BC populations were dominant, and West Alaska, Yukon and Asian populations were not included. In OA-2 fish, all regional populations appeared in the Gulf of Alaska, and South BC and Japanese populations were predominant. In OA-3 fish, West Alaska, Russian and Japanese populations were dominant, each occupying 25\%. The proportion of Asian (Russian and Japanese) populations increased with ocean age: $40 \%$ in OA-2, $50 \%$ in OA-3, and over 70\% in OA-4 fish. Most populations except for central Alaska were more abundant in southern waters (south of $52^{\circ} \mathrm{N}$ ).

A total of 28 otolith-marked chum salmon were found in the Gulf of Alaska. All of OA-1\&2 marked fish were released from hatcheries in SEAK $(n=22)$. OA-3\&4 marked fish were from Central Alaska $(n=3)$, SEAK $(n$ $=2)$ and Japan $(n=3)$.

Skinny chum salmon were frequently observed during the expedition. Chum salmon showed skinny condition (Condition Factor $<0.9$ ) in 15\% of the sample, most of which were OA-2 or 3 fish. In particular, OA-2 fish had an apparent lower condition factor than other age groups. SNP analysis showed that skinny chum salmon originated in all regional populations except for West Alaska. In OA-2 chum salmon, occurrence of skinny fish was 70-75\% in BC populations, and $30-50 \%$ in other populations. In OA-3 chum, the occurrence of skinny fish was $60 \%$ in the North \& Central BC populations, and around $20 \%$ in Russian and Japanese populations. The commercial catch of chum salmon in BC was extremely low in 2019 and 2020 (Grant et al. 2021; Velez-Espino et al. 2021). High occurrence of skinny chum salmon in winter might be a cause of these poor returns in BC populations.

Chum salmon mainly fed on euphausiids, pteropods, and jellyfish, and their stomach content index (SCI) was lowest among the pink, chum, sockeye, and coho salmon caught during the winter expedition (personal communication from Anton Khleborodov, Russia).

From these observations we propose three hypotheses: 1) not only the first winter, but also following winters, are a critical time for the survival of chum salmon; 2) chum salmon have a survival strategy that while overwintering they feed less and depend more on their energy accumulated in the previous summer/fall season; and 3) the energy content level prior to winter season and the winter habitat temperatures affect the survival of chum salmon. To test the hypotheses, in addition to winter expeditions, high-seas surveys during summer and fall are indispensable to assess the feeding and trophic condition of salmon.

\section{REFERENCES}

Beacham, T.D., J.R. Candy, S. Sato, S. Urawa, K.D. Le, and M. Wetklo. 2009. Stock origin of chum salmon (Oncorhynchus keta) in the Gulf of Alaska during winter as estimated with microsatellites. N. Pac. Anadr. Fish Comm. Bull. 5: 15-23. (Available at https://npafc.org)

All correspondence should be addressed to S. Urawa. 
Grant, S.C.H., B.L. MacDonald, D. Lewis, N. Wilson, J.L. Boldt, J. King, T. Ross, R.I. Perry, D.A. Patterson, K.A. Robinson, D.T. Selbie, C.G. Hannah, and A. Velez-Espino. 2021. Canada's 2020 report on recent Pacific salmon abundance and ecosystem trends. N. Pac. Anadr. Fish Comm. Doc. 1984. 9 pp. (Available at https://npafc.org)

Pakhomov, E.A., C. Deeg, S. Esenkulova, G. Foley, B.P.V. Hunt, A. Ivanov, H.K. Jung, G. Kantakov, A. Kanzeparova, A. Khleborodov, C. Neville, V. Radchenko, I. Shurpa, A. Slabinsky, A. Somov, S. Urawa, A. Vazhova, P.S. Vishnu, C. Waters, L. Weitkamp, M. Zuev, and R. Beamish. 2019. Summary of preliminary findings of the International Gulf of Alaska expedition onboard the R/V Professor Kaganovskiy during February 16-March 18, 2019. N. Pac. Anadr. Fish Comm. Doc. 1858. 25 pp. (Available at https://npafc.org)

Urawa, S., Y. Ishida, Y. Ueno, S. Takagi, G. Winans, and N. Davis. 1997. Genetic stock identification of chum salmon in the North Pacific Ocean and Bering Sea during the winter and summer of 1996. N. Pac. Anadr. Fish Comm. Doc. 259. 11 pp. (Available at https://npafc.org)

Urawa, S., T.D. Beacham, S. Sato, T. Kaga, B.A. Agler, R. Josephson, and M. Fukuwaka. 2016. Stock-specific abundance of chum salmon in the central Gulf of Alaska during winter. N. Pac. Anadr. Fish Comm. Bull. 6: 153-160. (Available at https://npafc.org)

Velez-Espino, A., B. Ramshaw, and S. Hamilton. 2021. Canadian salmon catch and enhanced salmon production 2017-2020. N. Pac. Anadr. Fish Comm. Doc. 1941. 13 pp. (Available at https://npafc.org) 